\title{
Incorporation of Carboplatin in Microporous Granular Calcium Phosphate Biphasic Matrix
}

\author{
Cleomar Copatti' ${ }^{1}$, N. H. A. Camargo ${ }^{2}$, E. Gemelli ${ }^{2}$ \\ ${ }^{1}$ Chemistry Department, Santa Catarina University, Joinville, Brazil \\ ${ }^{2}$ Mechanical Engineering Department, Santa Catarina University, Joinville, Brazil \\ Email: copattic@yahoo.com.br, dem2nhac@joinville.udesc.br, enori@joinville.udesc.br
}

Received December 2013

\begin{abstract}
The HA/ $\beta$-TCP biphasic bioceramics stand out on researches in different areas of biomedical applications. These bioceramics with microporous microstructures also stand out in biomedical applications on controlled drug release. This study aimed at the synthesis of the biphasic HA/ $\beta$-TCP powder, and at the elaboration and characterization of the microporous biphasic HA/ $\beta$-TCP granular biomaterial. The microporous granular material was elaborated through the process of ceramic powder sieving $(200 \mu \mathrm{m}<\mathrm{d}<500 \mu \mathrm{m}$ mesh sizes). The granular material was sintered at $1100^{\circ} \mathrm{C} / 2 \mathrm{~h}$, providing the microporous biphasic granular biomaterial. The drug loading in the biomaterial was performed through the high vacuum method. The results here presented are related to the synthesis method and elaboration of the biphasic biomaterial. The results obtained from the drug loading through the high vacuum method conducted the incorporation of the drug onto the surface and into the microporous granular biomaterial.
\end{abstract}

\section{Keywords}

Elaboration; Biphasic; Biomaterial; Microporosity; Drug

\section{Introduction}

The calcium phosphate bioceramics are widely studied and stand out in researches as biomaterials for bone reconstruction and defect repairing. They have also shown to be promising as matrices for controlled localized drug delivery [1]. This is due to their characteristics of non-toxicity and crystallographic compatibility and similarity with the human skeleton apatite [2]-[5]. The calcium phosphate bioceramics are targeted by tissue and material engineering, which is associated with the possibility of producing biomaterials with microporous architectures and physical, chemical and mechanical properties similar to the structure of bone tissue [6]. The calcium phosphate biphasic bioceramics stand out in researches as medication storage matrices to be posteriorly used as products for controlled drug release [7]-[9]. The first study is on loading of microporous bioceramics in the 1980s with the introduction of ceramic capsules of aluminum-calcium-phosphorous oxide [10].

It was found in the bibliography that the calcium phosphate bioceramics have been used in the treatment of

How to cite this paper: Copatti, C., Camargo, N.H.A. and Gemelli, E. (2014) Incorporation of Carboplatin in Microporous Granular Calcium Phosphate Biphasic Matrix. Journal of Biosciences and Medicines, 2, 30-35.

http://dx.doi.org/10.4236/***.2014.***** 
bone metastasis, osteoporosis and osteomyelitis [11]-[14]. This is due to the fact that these bioceramics provide an architecture capable of storing and protecting the medications inside their interconnected microporosities [15]-[17]. A drug delivery system is a technology which allows the drug to be released in the target site, not only to reduce the medications' side effects, but also to maximize the drug action [18]-[20]. There are many drug delivery models: polymer-based nanocapsules [21], carbon nanotubes [22] [23]. These dosage vehicles or drug transporters are subjected to different environmental conditions in the living organism. The major concern is about the dosage and the permanence time before the drug reaches its destination and localized release [24]. In general, oncological treatments with drugs are not selective; they reach the target cells, but can also destroy bone tissues in perfect state during its administration, whether it is oral or associated with the bone graft.

This study aimed at the synthesis of a calcium phosphate powder and at the elaboration of a microporous biphasic granular biomaterial for further incorporation and characterization of carboplatin in the microporosity and surface of the $60 \% \mathrm{HA} / 40 \% \beta$-TCP calcium phosphate biphasic biomaterial at a $70 \mathrm{mg}$ concentration. The high vacuum method was used for the deposition of $70 \mathrm{mg}$ of drugs on the surface and in the interior of the microporous granular biomaterial. The characterization studies were carried out with the use of many different techniques. The scanning electron microscopy technique was used for the characterization of the granular biomaterial's morphology and microstructure. It also served as a support for the drug identification after its incorporation in the biphasic granular biomaterial. The X-ray diffractometry served as a support for the identification of the biphasic biomaterial's phases before and after the loading with the drug. Finally, the infrared spectroscopy technique was used to identify the vibrational bands of the $\mathrm{OH}-, \mathrm{PO}_{4}^{3-}$ and $\mathrm{Pt}, \mathrm{NH} 3$ groups.

\section{Materials and Methods}

The synthesis of the calcium phosphate powder was carried out with the wet chemical method, through the reaction of dissolution/precipitation, which involves a $\mathrm{CaO}$ solid/liquid phase and a phosphoric acid solution. The elaboration of the biphasic biomaterial was carried out with the support of a high energy NETZSCH attrition mill with $2 \mathrm{~mm}$-diameter zirconium beads and distilled water. The process in the attrition mill was carried out with a solid/liquid concentration of 50\%/50\% volume. This process was kept under stirring for one hour, as described by [25] [26]. The colloidal suspension resulting from the attrition was dried in a rotary evaporator, providing the clustered HA $/ \beta$-TCP biphasic nanostructured powders. These powders went through a process of classification with sieves, going through a \#500 mesh and having the accumulated granular material recuperated by a \#200 mesh sieve. The granular material obtained was subjected to sintering at $1100^{\circ} \mathrm{C} / 2 \mathrm{~h}$, providing the microporous biphasic granular biomaterial.

The $450 \mathrm{mg}$ carboplatin was acquired from Tevacarbo. This drug was incorporated to the microporous biphasic granular biomaterial at a concentration of $70 \mathrm{mg} / 1 \mathrm{~g}$ of biphasic biomaterial. The high vacuum method was used to incorporate the drug to the biomaterial. This is a physical process which inhibits the modification of the chemical and physical characteristics of the medication and the biomaterial [11].

The studies of morphological and microstructural characterization were carried out with a Jeol JSM6701F scanning electron microscope, through the secondary electron (SE) system. These studies were carried out on the carboplatin powder and the microporous biphasic granular biomaterial. The X-ray diffractometry helped in the identification of the current phases of the biphasic biomaterial and the biomaterial loaded with the drug. The Fourier transform infrared spectroscopy (FTIR) technique allowed the identification of the drug's and the biphasic biomaterial's vibrational bands.

\section{Results and Discussions}

The results obtained from the morphological and microstructural characterization of the microporous biphasic granular biomaterials revealed, in their micrographs, the morphology of granules with irregular shapes and sizes between $200 \mu \mathrm{m}<\mathrm{d}<500 \mu \mathrm{m}$, as it can be observed in Figure 1(a). Another observation was the interconnected microporous microstructure of the granular biomaterial, as featured in Figure 1(b).

Figure 2(a) features the morphology of the carboplatin medication, where the morphology of thin rods with rectangular shapes were found indicating the drug (mannitol) loading, as well as the morphology of small crystals, scattered and agglomerated indicating the carboplatin's morphology. Figure 1(b) illustrates the microstructure of the biphasic biomaterial without drug loading. Figures 2(b) and 2(c) feature the microstructure of the biphasic biomaterial with $70 \mathrm{mg}$ drug loading. It is also noted, in the micrographs, the presence of a new 


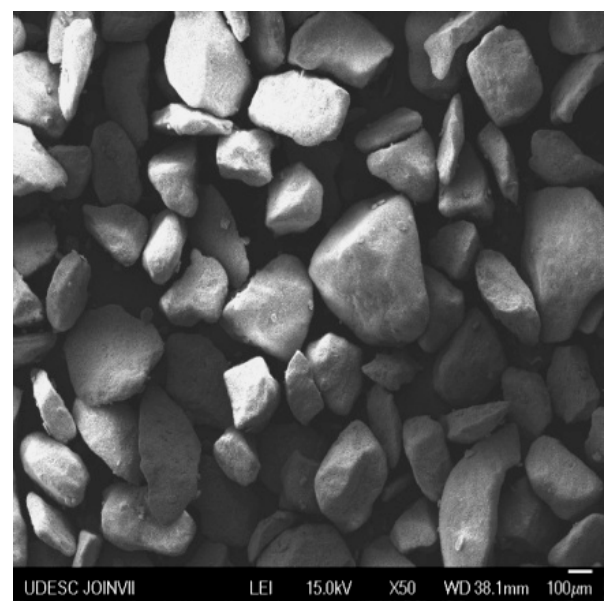

(a)

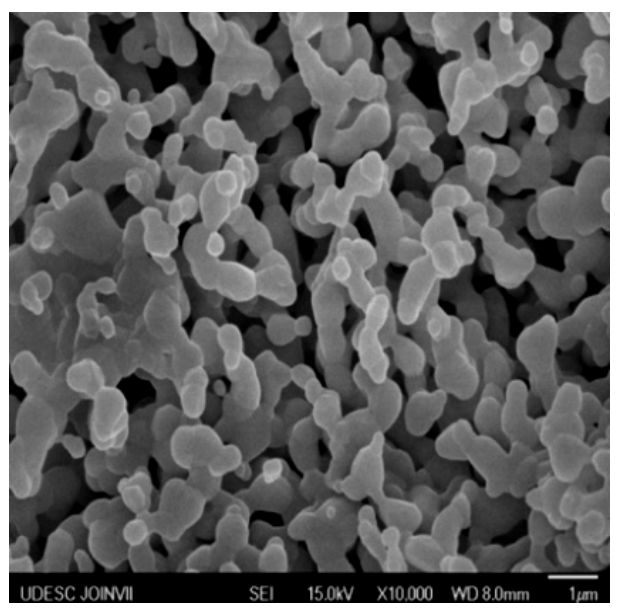

(b)

Figure 1. (a) Morphology of the HA/ $\beta$-TCP biphasic granular biomaterial HA/TCP- $\beta$; (b) Microstructure of the HA/ $\beta$-TCP biphasic granule.

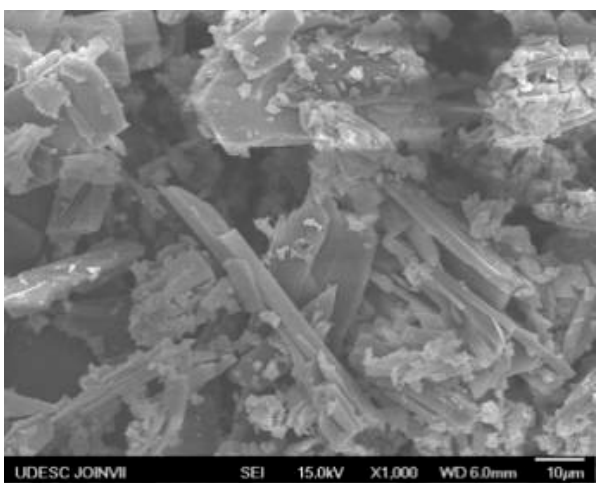

(a)

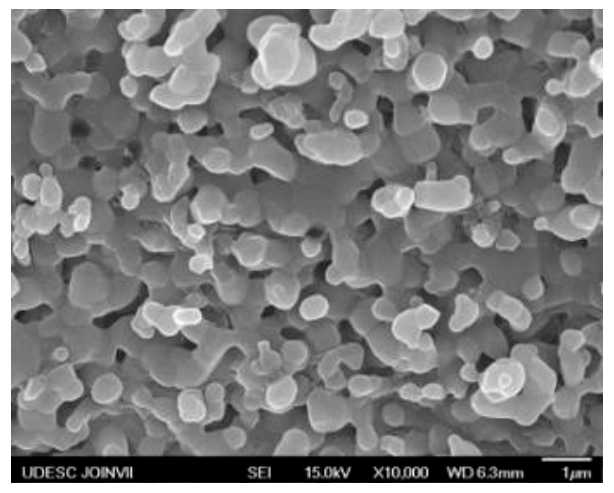

(b)

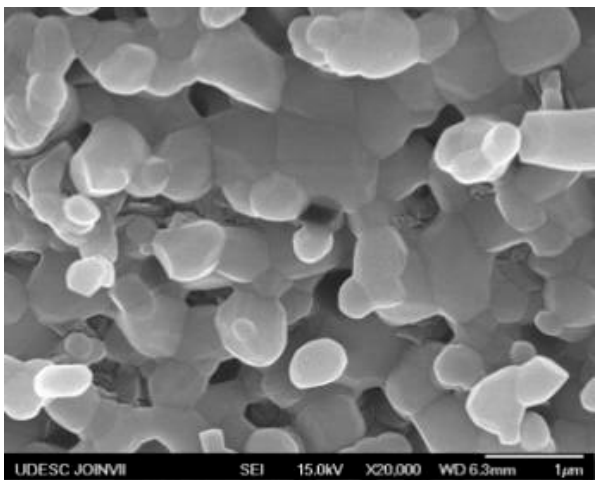

(c)

Figure 2. (a) Morphology of the drug; (b) Drug in the interface; (c) Drug in the interior of the biphasic biomaterial's microstructure.

morphology in the biphasic biomaterial's grain interface and in the interior of the biomaterial's microporosity (Figures 2(c)), indicating that the incorporation of the drug was successful.

The results obtained from the X-ray diffractometry on the microporous biphasic granular biomaterial clearly revealed, in their X-ray diffractograms, the presence of the hydroxyapatite and $\beta$-calcium phases (Figure 3). In Figure 3, the presence of well-defined peaks of the stoichiometric hydroxyapatite phase in the composition $\mathrm{Ca}_{10}\left(\mathrm{PO}_{4}\right)_{6}(\mathrm{OH})_{2}$ can be noticed, with main diffraction plane of [211]. Peaks of lower intensity for the $\beta$-calcium 
phosphate (Whitlockite) phase, in the $\beta$-Ca $3\left(\mathrm{PO}_{4}\right)_{2}$ composition, with Rhombohedral crystal system and main diffraction plane of [021] were also found.

Figure 4 reveals the spectrogram obtained from the microporous biphasic granular biomaterial. In the spectrogram, vibrational bands of the OH-groups in $3,575 \mathrm{~cm}^{-1}, 1,739 \mathrm{~cm}^{-1}, 632 \mathrm{~cm}^{-1}$ and $1,080 \mathrm{~cm}^{-1}, 1,018 \mathrm{~cm}^{-1}$, $594 \mathrm{~cm}^{-1}, 567 \mathrm{~cm}^{-1}$ representing the $\mathrm{PO}_{4}$ vibrational groups.

Figure 5 shows the spectrogram obtained from the biphasic biomaterial after the drug loading. What can be observed is the presence of typical hydroxyl and phosphate groups, representative of the biphasic biomaterial, and the groups representative of the drug, $\mathrm{NH}_{3}$ with multiple peaks between $3,200-2,400 \mathrm{~cm}^{-1}$ and Pt between 585 and $380 \mathrm{~cm}^{-1}$. It was also found that there is an overlap in the vibrational bands of the $\mathrm{PO}_{4}$ and $\mathrm{OH}^{-}$groups with the $\mathrm{NH}_{3}, \mathrm{C}=\mathrm{O}, \mathrm{C}, \mathrm{CH}, \mathrm{CH}_{2}$, Pt groups. This can be explained by the fact that the drug has functional groups very close to those of the biphasic biomaterial.

\section{Conclusion}

The wet chemical synthesis method provided the calcium phosphate biphasic powder. The X-ray diffractometry evidenced the HA and $\beta$-TCP phases in the microporous biphasic granular biomaterial. The high vacuum method proved to be efficient for the incorporation of the drug onto the grain surface and to the interior of the calcium phosphate biphasic biomaterial's microporosity. The images obtained with the scanning electron microscopy revealed the presence of the drug on the biphasic biomaterial's surface and in the interior of the biomaterial's microporosity. The results obtained through the infrared spectroscopy on the microporous biphasic granular biomaterial with the drug presented an overlap in the vibrational bands, especially the functional groups $\mathrm{OH}^{-}, \mathrm{NH}_{3}, \mathrm{C}=\mathrm{O}, \mathrm{C}, \mathrm{CH}, \mathrm{CH}_{2}, \mathrm{Pt}$, which present themselves as similar between the biphasic biomaterial and the drug.

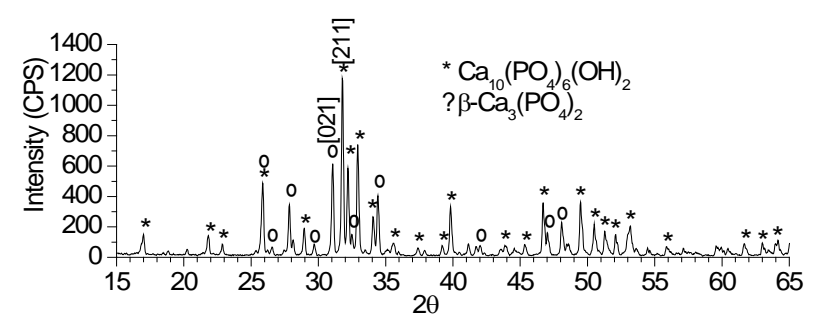

Figure 3. X-ray diffractogram obtained from the microporous biphasic granular biomaterial.

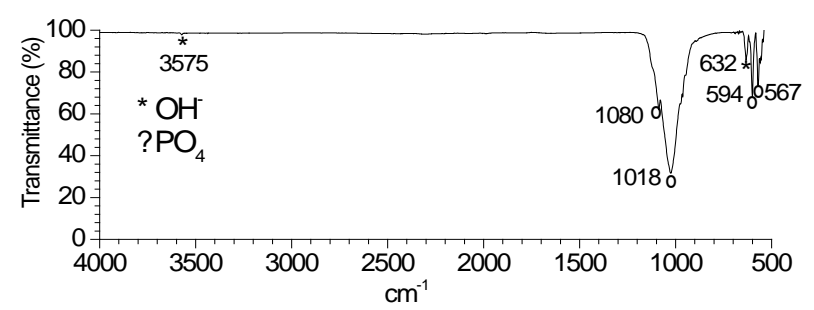

Figure 4. Spectrogram obtained from $\mathrm{HA} / \beta$-TCP granular biomaterial.

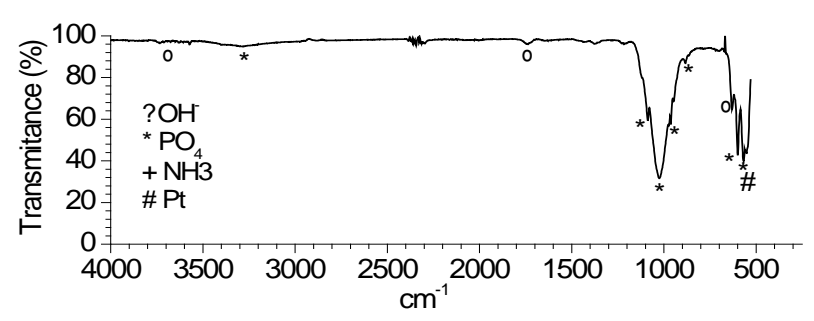

Figure 5. Spectrogram obtained from HA/ $\beta$-TCP granular biomaterial with drug. 
The vacuum incorporation technique has shown to be promising for not presenting modification in the structures of the biphasic biomaterial as well as of the drug. Another relevant point of this method is associated to its simplicity and low cost, being easily adapted to a production line at an industrial level.

\section{References}

[1] Victor, S.P. and Sampath Kumar, T.S. (2008) BCP Ceramic Microspheres as Drug Delivery Carriers: Synthesis, Characterisation and Doxycycline Release. Journal of Materials Science: Materials in Medicine, 19, 283-290. http://dx.doi.org/10.1007/s10856-006-0044-7

[2] Camargo, N.H.A., et al. (2009) Synthesis and Characterization of Nanostructured Ceramic Powders of Calcium Phosphate and Hydroxyapatite for Dental Applications. Key Engineering Materials, 398, 619-622.

[3] Ramay, H.R.R. and Zhang, M. (2004) Biphasic Calcium Phosphate Nanocomposite Porous Scaffolds for Load-Bearing Bone Tissue Engineering. Biomaterials, 25, 5171-5180 http://dx.doi.org/10.1016/j.biomaterials.2003.12.023

[4] Ghanaati, S., Barbeck, M., Orth, C., Willershausen, I., Thimm, B.W., et al. (2010) Influence of $\beta$-Tricalcium Phosphate Granule Size and Morphology on Tissue Reaction in Vivo. Acta Biomaterialia, 6, 4476-4487.

[5] Dorozhkin, S.V. (2012) Biphasic, Triphasic and Multiphasic Calcium Orthophosphates. Acta Biomaterialia, 8, $963-977$. http://dx.doi.org/10.1016/j.actbio.2011.09.003.

[6] Ghanaati, S., Barbeck, M., Orth, C. andWillershausen, I., et al. (2010) Influence of $\beta$-Tricalcium Phosphate Granule Size and Morphology on Tissuereaction in Vivo. Acta Biomaterialia, 6, 4476-4487. http://dx.doi.org/10.1016/j.actbio.2010.07.006.

[7] Ginebra, M.P., Canal, C., Espanol, M., Pastorino, D. and E.B. Montufar, (2012) Calcium Phosphate Cements as Drug Delivery Materials. Advanced Drug Delivery Reviews, 64, 1090-1110 http://dx.doi.org/10.1016/j.addr.2012.01.008

[8] Ginebra, M.P., Traykova, T. and Planell, J.A. (2006) Calcium Phosphate Cements as Bone Drug Delivery Systems: A Review. Journal of Controlled Release, 113, 102-110. http://dx.doi.org/10.1016/j.jconrel.2006.04.007

[9] Arar, H.H. and Bajpai, P.K. (1992) Insulin Delivery by Zinc Calcium Phosphate Ceramics. Biomedical Sciences Instrumentation, 28, 173-178.

[10] Velard, F. Braux, J. and Amedee, J. (2013) Patrice Laquerriere Inflammatory Cell Response to Calcium Phosphate Biomaterial Particles: An Overview. Acta Biomaterialia, 9, 4956-4963. http://dx.doi.org/10.1016/j.actbio.2012.09.035

[11] Copatti, C., Daiara F.S, Correa, P. and Camargo, N.H.A. (2012) Elaboração e caracterização de biomaterial nanoestruturado granulado bifásico ha/tcp-b para aplicações no tratamento da estrutura óssea. http://www.cbecimat.com.br/trabalhos-completos-cbecimat.php.

[12] Josse, S., Faucheux, C., Soueidan, A., et al. (2005) Novel Biomaterials for Bisphosphonate Delivery. Biomaterials, 26, 2073-2080.

[13] Busse, B., Jobke, B., Hahn, M., Priemel, M., Niecke, M., Seitz, S., Zustin, J., Semler, J. and Amling, M. (2010) Effects of Strontium Ranelate Administration on Bisphosphonate-Altered Hydroxyapatite: Matrix Incorporation of Strontium Is Accompanied by Changes in Mineralization and Microstructure. Acta Biomaterialia, 6, 4513-4521. http://dx.doi.org/10.1016/j.actbio.2010.07.019

[14] Camargo, N.H.A., de Lima, S. A. and Gemelli, E. (2012) Synthesis and Characterization of Hydroxyapatite/TiO $2 n$ Nanocomposites for Bone Tissue Regeneration. American Journal of Biomedical Engineering, 2, 41-47,

[15] Luís Fernando Pereira: Elaboração e Caracterização de Biomateriais Nanocompósitos Granulados: universidade do estado de santa catarina, udesc centro de ciências tecnológicas, cct curso de engenharia mecânica: trabalho de conclusão de curso.

[16] Ginebra, M.P., Espanol, M., Montufar, E.B., Perez, R.A. and Mestres G. (2010) New Processing Approaches in Calcium Phosphate Cements and Their Applications in Regenerative Medicine. Acta Biomaterialia, 6, 2863-2873. http://dx.doi.org/10.1016/j.actbio.2010.01.036

[17] Kojima, C., Suehiro, T., Watanabe, K., Ogawa, M., Fukuhara, A., Nishisaka, E., Harada, A., Kono, K., Inui, T. and Magata, Y. (2013) Doxorubicin-Conjugated Dendrimer/Collagen Hybrid Gels for Metastasis-Associated Drug Delivery Systems. Acta Biomaterialia, 9, 5673-5680. http://dx.doi.org/10.1016/j.actbio.2012.11.013

[18] D’Este, M. and Eglin, D. (2013) Hydrogels in Calcium Phosphate Moldable and Injectable Boné Substitutes: Sticky Excipients or Advanced 3-D Carriers? Acta Biomaterialia, 9, 5421-5430. http://dx.doi.org/10.1016/j.actbio.2012.11.022

[19] Mahkam, M., Hosseinzadeh, F. and Galehassadi, M. (2012) Preparation of Ionic Liquid Functionalized Silica Nanoparticles for Oral Drug Delvery. Jornal of Biomaterials and Nanobiotechenology, 3, 391-395

[20] Mahkam, M., Hosseinzadeh, F. and Galehassadi, M. (2012) Preparation of Ionic Liquid Functionalized Silica Nanopar- 
ticles for Oral Drug Delvery. Journal of Biomaterials and Nanobiotechenology, 3, 391-395. http://dx.doi.org/10.1016/j.ijpharm.2009.10.018

[21] Mora-Huertas, C.E., Fessi, H. and Elaissari, A. (2010) Polymer-Based Nanocapsules for Drug Delivery. International Journal of Pharmaceutics, 385, 113-142. http://dx.doi.org/10.1016/j.ijpharm.2009.10.018

[22] Bianco, A., Kostarelos, K. and Prato, M. (2005) Applications of Carbon Nanotubes in Drug Delivery. Current Opinion in Chemical Biology, 9, 674-679.

[23] Wamocha, H.L., Misak, H.E., Song, Z., Chu, H.Y., Chen, Y.Y., Asmatulu, R., Yang, S.-Y. and Ho, J.C. (2013) Cytotoxicity of Release Products from Magnetic Nanocomposites in Targeted Drug Delivery. Journal of Biomaterials Applications, 27, 661.

[24] Friend, D.R. (1991) Colon-Specific Drug Delivery. Advanced Drug Delivery Reviews, 7, 149-199.

[25] Dalmônico, G.M.L. (2011) Síntese e caracterização de fosfato de cálcio e de hidroxiapatita: Elaboração de composições bifásicas HA/TCP- $\beta$ para aplicações biomédicas. Dissertação de mestrado em Ciência e Engenharia de Materiais, Universidade do Estado de Santa Catarina, Joinville-SC, 95.

[26] De Lima, S., Souza, J., Camargo, N., Pupio, F., Santos, R. and Gemelli, E. (2008) Síntese e Caracterização de Pós Nanoestruturados de Hidroxiapatita. 5 Congresso Latino Americano de 2008órgãos Artificiais e Biomateriais, COLAOB' 2008, Ouro Preto, 1-6. 